\title{
Prevalence of Nosocomial Infections in Swiss CHILDREN's Hospitals
}

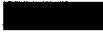 \\ Kathrin Muihlemann, MD, PhD; Christine Franzini; Christoph Aebi, MD; Christoph Berger, MD; David Nadal, MD; \\ Jody Stähelin, MD; Hanspeter Gnehm, MD; Klara Posfay-Barbe, MD; Alain Gervaix, MD; Hugo Sax, MD; Ulrich Heininger, MD; \\ Jan Bonhoeffer, MD; Gerhard Eich, MD; Christian Kind, MD; Christiane Petignat, MD; Pietro Scalfaro, MD
}

\begin{abstract}
OBJECTIVE: To acquire data on pediatric nosocomial infections (NIs), which are associated with substantial morbidity and mortality and for which data are scarce.

DESIGN: Prevalence survey and evaluation of a new comorbidity index.

SETTING: Seven Swiss pediatric hospitals.

PATIENTS: Those hospitalized for at least 24 hours in a medical, surgical, intensive care, or intermediate care ward.

RESULTS: Thirty-five NIs were observed among 520 patients $(6.7 \%$; range per hospital, $1.4 \%$ to $11.8 \%)$. Bacteremia was most frequent (2.5 per 100 patients), followed by urinary tract infection (1.3 per 100 patients) and surgical-site infection (1.1 per 100 patients; 3.2 per 100 patients undergoing surgery). The median duration until the onset of infection was 19 days. Independent risk factors for NI were age between 1 and 12 months, a comor-
\end{abstract}

bidity score of 2 or greater, and a urinary catheter. Among surgical patients, an American Society of Anesthesiologists (ASA) score of 2 or greater was associated with any type of NI $(P=.03)$. Enterobacteriaceae were the most frequent cause of NI, followed by coagulase-negative staphylococci; viruses were rarely the cause.

CONCLUSIONS: This national prevalence survey yielded valuable information about the rate and risk factors of pediatric NI. A new comorbidity score showed promising performance. ASA score may be a predictor of NI. The season in which a prevalence survey is conducted must be considered, as this determines whether seasonal viral infections are observed. Periodic prevalence surveys are a simple and cost-effective method for assessing NI and comparing rates among pediatric hospitals (Infect Control Hosp Epidemiol 2004;25:765-771).
Nosocomial infections are associated with a high burden of excess morbidity and mortality in both adults and children.1,2 In Switzerland, as in other countries, an average of $5 \%$ to $10 \%$ of all hospitalized adults acquire a nosocomial infection. ${ }^{1,3,4}$

Children's hospitals serve a unique patient population, one that differs in many respects, including infection control, from the adult patient population. ${ }^{5}$ However, compared with adults, few data are available concerning nosocomial infections among children. Their frequency seems to be, on average, lower among children and differs substantially depending on age group and hospital unit surveyed..$^{6-14}$ For example, the highest nosocomial infection rates have been described for neonates, infants, and patients in intensive care or surgical units.

Surveillance is important for controlling nosocomial infections..$^{15}$ However, depending on the methodology employed, assessing nosocomial infections can be costly.
Prevalence surveys are the least costly type of surveillance for nosocomial infections and provide valuable information, especially when repeated at regular intervals. ${ }^{3,4,6}$ Relatively small numbers of patients in high-risk groups (eg, patients in pediatric and neonatal intensive care units) may hamper the success of prevalence studies. However, prevalence surveys can provide valuable information on the overall rate of pediatric nosocomial infections and, in multicenter studies, can also provide information on high-risk patients. ${ }^{6,12,14}$

Comorbidity scores are used for case-mix adjustment in surveys of nosocomial infections among the general adult patient population. For example, the Charlson score, the Karnofsky index, and the McCabe and Jackson classification have been shown to correlate with the risk of nosocomial infection in prevalence surveys. ${ }^{3,4}$ However, no such score exists for the general pediatric patient population.

Dr. Mühlemann, Ms. Franzini, and Dr. Aebi are from the University Hospital, Bern, Switzerland. Drs. Berger and Nadal are from the University Children's Hospital, Zürich, Switzerland. Drs. Stähelin and Gnehm are from the Children's Hospital, Aarau, Switzerland. Drs. PosfayBarbe and Gervaix are from the University Children's Hospital; and Dr. Sax is from the Infection Control Program, University of Geneva Hospitals, Geneva, Switzerland. Drs. Heininger and Bonhoeffer are from the University Children's Hospital, Basel, Switzerland. Drs. Eich and Kind are from the Children's Hospital, St. Gallen, Switzerland. Drs. Petignat and Scalfaro are from the University Children's Hospital, Lausanne, Switzerland.

Address reprint requests to Kathrin Mühlemann, MD, PhD, Institute for Infectious Diseases, University of Bern, Friedbühlstrasse 51 , CH-3010 Bern, Switzerland.

The authors thank the members of the Swiss-Noso working group (Enos Bernasconi, Patrick Francioli, Kathrin Mïhlemann, Didier Pittet, Pierre-Alain Raeber, Christian Ruef, Hugo Sax, Hans Siegrist, Nicolas Troillet, and Andreas Widmer) for their support and encouragement. 
TABLE 1

SCORES OF THE COMORBIDITY INDEX FOR THE PATIENTS

\begin{tabular}{lc}
\hline IIIness or Condition & Score \\
\hline Asthma & 1 \\
Cystic fibrosis & 2 \\
Other chronic pulmonary disease & 1 \\
Neoplasm-solid tumor & 2 \\
Leukemia & 2 \\
Lymphoma & 2 \\
Congenital immunodeficiency & 2 \\
HIV infection & 2 \\
Metabolic disease & 1 \\
Vesicoureteral reflux & 2 \\
Congenital heart defect-cyanotic & 2 \\
Congenital heart defect-non-cyanotic & 1 \\
Liver cirrhosis & 2 \\
Malformation syndromes & 1 \\
Total & Sum of fulfilled \\
& criteria for a \\
& given study patient \\
\hline
\end{tabular}

HIV = human immunodeficiency virus.

This article reports the results of a prevalence survey of nosocomial infections in Swiss children's hospitals conducted in May 2000. A special feature of this study was the evaluation of a new comorbidity index for children.

\section{METHODS}

A prevalence survey was performed in seven pediatric hospitals in Switzerland between May 17 and May 19, 2000. Data were collected from all medical and surgical wards and intensive and intermediate care units. Wards with a patient stay of less than 24 hours were excluded. ${ }^{3,4}$ Intensive care units were defined as units with intensive monitoring and artificial ventilation. In intermediate care units, intensive monitoring was performed, but not artificial ventilation. The total number of hospital beds surveyed was 969 (average number per hospital, 138 beds; range, 72 to 247 beds). This covered approximately $70 \%$ of all Swiss pediatric hospital beds.

The study population consisted of all patients hospitalized for at least 24 hours at each of the seven hospitals. A standardized questionnaire was completed for every patient. Sociodemographic and clinical data were ascertained by reviewing nursing and medical charts and, if necessary, by receiving additional information from the hospital staff. No additional clinical examinations or analyses were performed.

All active (ie, symptomatic or under treatment) nosocomial infections present on the study day or during 1 of the 6 previous days were documented. Surgical-site infections were included when evident if they had onset within 30 days following surgery, or within 1 year in the case of infection associated with an implant. A nosocomial infection was defined as an infection occurring 48 hours or more after hospitalization or birth and not demonstrating any sign of incubation or illness at admission. In addition, a nosocomial infection had to meet all requirements of the standardized and minimally adapted definitions of the Centers for Disease Control and Prevention for pediatric patients. ${ }^{16}$ The important adaptation was that the age restriction in the specific definitions for pneumonia and lower respiratory tract infection was raised from 1 to 7 years.

The primary diagnosis was classified according to the 20 diagnostic groups defined by the International Classification of Diseases, 9th revision, Clinical Modification. ${ }^{17}$

A new score based on an adapted version of the Charlson score was created for the assessment of comorbidity (Table 1). ${ }^{18}$ For surgical patients, the American Society of Anesthesiologists (ASA) score was obtained.

Information was obtained concerning the presence of indwelling devices and the consumption of antibiotics during the 7 days before a patient met the criteria for nosocomial infection or during the 7 days before the study day. Data were also collected concerning surgery occurring during the 30 -day period preceding the study day (1 year in the case of an implant). If a patient underwent several interventions, data were collected for the surgery associated with the highest expected risk for nosocomial infection.

The questionnaire was tested at each hospital prior to the study. During the study, every questionnaire was reviewed and, if necessary, completed by the hospital coordinator.

Risk factors for nosocomial infection identified by univariate analysis were entered into a logistic regression model (StatView, version 5.0; SAS Institute, Inc., Cary, NC), with the exception of variables that were collected only for patients undergoing surgery. The final model comprised all variables that remained significantly associated with nosocomial infection on adjustment.

Proportions were compared using the chi-square or Fisher's exact test as appropriate. Differences between means were assessed using Student's $t$ test. A two-tailed $P$ value of .05 or less was used to define statistical significance for all analyses.

\section{RESULTS}

The study population consisted of 520 patients (range per hospital, 45 to 103 patients). Medical wards contributed most of the patients $(48.0 \%)$, followed by surgical wards $(31.7 \%)$, intensive care units $(10.2 \%)$, and intermediate care units $(10.2 \%)$ (Table 2$)$. Almost half (48.0\%) of the study patients were between 5 and 16 years old and neonates comprised $22.3 \%$ of the patients. Approximately one-third of the patients required intensive care $(28.8 \%)$ or had surgery $(35.5 \%)$ prior to the study day. A high proportion of patients $(63.9 \%)$ had an intravascular catheter; $8.3 \%$ had a bladder catheter and $6.7 \%$ were intu- 
bated at some time during their hospitalization before the study day.

A total of 35 nosocomial infections were found among 34 children for an overall attack rate of 6.7 nosocomial infections per 100 patients $(95 \%$ confidence interval $\left[\mathrm{CI}_{95}\right], 4.6$ to 8.8$)$. The infection rate ranged between $1.4 \%$ and $11.8 \%$ in the different hospitals. The most frequent type of nosocomial infection was bloodstream infection (37.1\%; 2.5 per 100 patients), followed by urinary tract infection (20\%; 1.3 per 100 patients) and surgical-site infection (17.1\%; 1.1 per 100 patients and 3.2 per 100 patients who underwent surgery) (Table 3). Upper and lower respiratory tract infections $(0.3$ and 1.0 per 100 patients, respectively) and gastrointestinal infections ( 0.4 per 100 patients) were rare (Table 3 ). The infection rate was highest among infants 1 to 12 months old (14.5 per 100 patients), followed by neonates (6.9 per 100 patients), young children (5.6 per 100 patients), and older children (4.4 per 100 patients) (Table 2). Patients in intermediate care units had a higher nosocomial infection rate (13.2 per 100 patients) than did patients in intensive care units (7.5 per 100 patients) or patients in surgical (3.6 per 100 patients) or medical wards (7.2 per 100 patients). High rates were also observed for patients with a comorbidity score of 2 or greater (16.4 per 100 patients), and for patients with a urinary catheter (14.0 per 100 patients). The median duration until the onset of a nosocomial infection was 19 days (range, 2 to 145 days).

Endogenous risk factors for nosocomial infection included age between 1 and 12 months (odds ratio [OR], $3.67 ; \mathrm{CI}_{95}, 1.55$ to 8.69 ), a comorbidity score of 2 or greater $\left(\mathrm{OR}, 2.85 ; \mathrm{CI}_{95}, 1.20\right.$ to 6.80$)$, and hospitalization due to a neoplasm (OR, 4.76; $\mathrm{CI}_{95}, 1.63$ to 14.28 ) or congenital illness (OR, 4.16; $\mathrm{CI}_{95}, 1.47$ to 11.10) (Table 2). Exogenous risk factors included a stay in an intermediate care unit $\left(\mathrm{OR}, 4.16 ; \mathrm{CI}_{95}, 1.29\right.$ to 12.5$)$, surgery during the past 30 days (or 1 year in the case of placement of a foreign body; $\mathrm{OR}, 2.14 ; \mathrm{CI}_{95}, 1.06$ to 4.31 ), and the presence of an intravascular catheter (OR, 2.35, $\mathrm{CI}_{95}, 1.02$ to 5.45$)$ or a urinary catheter (OR, 2.60; $\mathrm{CI}_{95}, 1.01$ to 6.68) (Table 2). In the logistic regression model, independent risk factors for nosocomial infection were age between 1 and 12 months, a comorbidity score of 2 or greater, and the presence of a urinary catheter (Table 4).

Among surgical patients $(n=185)$, an ASA score of 2 or greater was significantly associated with any type of nosocomial infection (chi-square test for trend, $P=.03$ ) (Table 2). Five of 13 bloodstream infections were associated with an intravascular catheter, 4 of 7 urinary tract infections with a urinary catheter, and 1 of 2 pneumonias with mechanical ventilation.

A pathogen was isolated for 24 of the 35 nosocomial infections. A single microorganism was found in $83.3 \%$ of these infections, and $16.7 \%$ were polymicrobial infections. Enterobacteriaceae (excluding Escherichia coli) were the most frequent pathogens $(37.5 \%)$ isolated, followed by coagulase-negative staphylococci (29.2\%) (Table 5).

\section{DISCUSSION}

In this pediatric multicenter survey, the overall prevalence of nosocomial infections was $6.7 \%$. The observed nosocomial infection rate varied among the seven participating hospitals. These differences did not reach statistical significance, although the relatively small number of patients surveyed in some of the hospitals did not permit calculation of standardized or adjusted nosocomial infection rates. ${ }^{4,19}$ The nosocomial infection rate observed in this study lies within the range of infection rates $(2.3 \%$ to $12.6 \%)$ reported from earlier pediatric studies, but comparisons are hampered by the use of different methods in different studies. ${ }^{6,710,12}$ Published studies either used several types of longitudinal surveys, $7,9,10,20,21$ concentrated on high-risk populations, ${ }^{8,9,11,14}$ or both.

Consistent with earlier findings, the frequency of nosocomial infections was highest among infants. ${ }^{7}$ In the current study, intermediate care units were found to have the highest infection rate (13.2 per 100 patients), which was even higher than that observed in intensive care units. A comparison with other published studies is not possible, as no earlier study differentiated between these two types of units.

Our data confirm the relatively high proportion of bloodstream infections among pediatric patients, which contrasts with the predominance of urinary tract infections and surgical-site infections among adults. $6,7,10,11,14$ Our rate of 2.5 bloodstream infections per 100 patients is higher than that observed by others, but these studies differed in methods used. ${ }^{7,10}$

The rate of urinary tract infections (1.3 per 100 patients) was well within the previously reported range ( 0.36 to 5.2 per 100 patients) and was less than that reported among adults. ${ }^{3,6,7,10-12,14}$

Surgical-site infections were the third most frequent nosocomial infection in this study. The observed rate (3.2 per 100 patients undergoing surgery) is relatively high compared with other studies. The rate is also high considering the fact that, in a prevalence survey, a considerable proportion of postdischarge infections (approximately $35 \%$ ) are usually missed..$^{22}$ In this study, the proportion of patients with an ASA score of 2 or greater was significantly higher than that in another study. ${ }^{21}$ In a prevalence study, patients with a long hospital stay have an increased chance of being surveyed and they also have an increased risk of nosocomial infection. This may be reflected in the comparatively high frequency of surgicalsite infections observed in this study.

Respiratory tract infection is a common clinical manifestation of nosocomial infection in children. ${ }^{6,7,10-12,14}$ The low rate of lower respiratory tract infections observed in the current study (1.0 per 100 patients) is comparable to previously reported rates. ${ }^{7.11,14} \mathrm{As}$ in adults, nosocomial lower respiratory tract infections in children are strongly associated with artificial ventilation. ${ }^{6,11}$ Lower respiratory tract infections are more common in pediatric intensive care units than in neonatal units. ${ }^{10,11}$ However, an additional, unique feature of pediatric nosocomial res- 
TABLE 2

Characteristics of the 520 Patients From the Seven Children's Hospitals and Risk Factors for Nosocomial. Infections on UNIVARIATE ANALYSIS

\begin{tabular}{|c|c|c|c|c|c|}
\hline & Infected & $\begin{array}{l}\text { Not } \\
\text { Infected }\end{array}$ & $\mathbf{O} \mathbf{R}^{*}$ & $\mathrm{Cl}_{95}$ & $\boldsymbol{P}$ \\
\hline No. of patients ${ }^{\dagger}$ & 35 & 486 & & & \\
\hline \multicolumn{6}{|l|}{ Ward or unit (\%) } \\
\hline Surgical & $6(17.1)$ & $159(32.7)$ & Reference & & .1 \\
\hline Intensive care & $4(11.4)$ & $49(10.1)$ & 2.17 & $0.58-8.33$ & \\
\hline Intermediate care & $7(20.0)$ & $46(9.4)$ & 4.16 & $1.29-12.5$ & \\
\hline Medical & $18(51.4)$ & $232(47.7)$ & 2.08 & $0.80-5.55$ & \\
\hline \multicolumn{6}{|l|}{ Age (\%) } \\
\hline Neonate & $8(22.9)$ & $108(22.3)$ & 1.29 & $0.40-4.20$ & \\
\hline 1 to $12 \mathrm{mo}$ & $12(34.3)$ & $71(14.6)$ & 3.67 & $1.55-8.69$ & .003 \\
\hline 13 to $48 \mathrm{mo}$ & $4(11.4)$ & $67(13.8)$ & 1.61 & $0.62-4.11$ & \\
\hline 5 to $16 \mathrm{y}$ & $11(31.4)$ & $239(49.2)$ & Reference & & .01 \\
\hline \multicolumn{6}{|l|}{ Hospital (\%) } \\
\hline A & $3(8.6)$ & $42(8.6)$ & Reference & & .09 \\
\hline $\mathrm{B}$ & $1(2.9)$ & $71(14.6)$ & 0.19 & $0.01-1.96$ & \\
\hline $\mathrm{C}$ & $2(5.7)$ & $82(16.9)$ & 0.34 & $0.05-2.12$ & \\
\hline $\mathrm{D}$ & $10(28.6)$ & $76(15.6)$ & 1.85 & $0.48-7.14$ & \\
\hline $\mathrm{E}$ & $7(20.0)$ & $58(11.9)$ & 1.69 & $0.41-7.14$ & \\
\hline $\mathrm{F}$ & $5(14.3)$ & $61(12.6)$ & 1.14 & $0.26-5.26$ & \\
\hline $\mathrm{G}$ & $7(20.0)$ & $96(19.8)$ & 1.02 & $0.25-4.16$ & \\
\hline Male (\%) & $24(68.6)$ & $247(50.9)$ & 1.99 & $0.95-4.16$ & .06 \\
\hline Median duration of stay, $d^{\ddagger}$ & 30.0 & 12.0 & & & $<.001$ \\
\hline $\begin{array}{l}\text { Median duration of stay before } \\
\text { study day, } d\end{array}$ & 28.0 & 5.0 & & & $<.001$ \\
\hline Emergency referral (\%) & $23(65.7)$ & $315(64.8)$ & 1.04 & $0.50-2.14$ & .91 \\
\hline Surgery $(\%)$ & $18(51.4)$ & $167(34.4)$ & 2.14 & $1.06-4.31$ & .02 \\
\hline $\begin{array}{l}\text { Intensive care unit before } \\
\text { study day (\%) }\end{array}$ & $14(40.0)$ & $136(28.0)$ & 1.71 & $0.84-3.41$ & .13 \\
\hline \multicolumn{6}{|l|}{ Hospitalized for $(\%)^{8}$} \\
\hline Infection & $6(17.1)$ & $115(23.7)$ & 1.05 & $0.36-3.03$ & \\
\hline Neoplasm & $7(20.0)$ & $30(6.2)$ & 4.76 & $1.63-14.28$ & \\
\hline Congenital illness & $8(22.9)$ & $40(8.2)$ & 4.16 & $1.47-11.1$ & \\
\hline Perinatal illness & $3(8.6)$ & $71(14.6)$ & 0.85 & $0.22-3.22$ & \\
\hline Trauma & $2(5.7)$ & $49(10.1)$ & 0.82 & $0.17-4.00$ & \\
\hline Other & $9(25.7)$ & $181(37.3)$ & Reference & & .001 \\
\hline \multicolumn{6}{|l|}{ Comorbidity score (\%)\| } \\
\hline 0 & $21(60.0)$ & $353(72.6)$ & Reference & & .04 \\
\hline 1 & $5(14.3)$ & $78(16.0)$ & 1.07 & $0.39-2.94$ & .88 \\
\hline 2 & $8(22.9)$ & $49(10.1)$ & 2.74 & $1.19-6.32$ & .01 \\
\hline$>2$ & $1(2.9)$ & $6(1.2)$ & & & \\
\hline Intravascular catheter (\%) & $28(80.0)$ & $305(62.8)$ & 2.36 & $1.01-5.51$ & .04 \\
\hline Central catheter & $8(22.9)$ & $54(11.1)$ & 2.35 & $1.02-5.45$ & .03 \\
\hline Urinary catheter $(\%)$ & $6(17.1)$ & $37(7.6)$ & 2.60 & $1.01-6.68$ & .04 \\
\hline Antibiotic prophylaxis (\%) & $13(37.1)$ & $115(23.7)$ & & & \\
\hline Surgical & $8(61.5)$ & $52(45.2)$ & & & \\
\hline Other & $3(23.0)$ & $65(56.5)$ & & & \\
\hline \multicolumn{6}{|c|}{$\begin{array}{l}\text { American Society of Anesthesiologists } \\
\text { score (\%) }{ }^{\mathrm{q}}\end{array}$} \\
\hline 1 & $1(5.8)$ & $62(38.0)$ & Reference & & .03 \\
\hline 2 & $8(47.1)$ & $50(30.7)$ & 10.00 & $1.20-100$ & \\
\hline 3 & $8(47.1)$ & $42(25.8)$ & 10.00 & $1.17-100$ & \\
\hline 4 & $0(0)$ & $9(5.5)$ & & & \\
\hline
\end{tabular}


TABLE 2 (cont'd)

Characteristics of the 520 Patients From the Seven Children's Hospitals and Risk Factors for Nosocomial Infections on UNIVARIATE ANALYSIS

\begin{tabular}{lcccc}
\hline & Infected & $\begin{array}{c}\text { Not } \\
\text { Infected }\end{array}$ & OR* $^{*}$ & $\mathbf{C I}_{\mathbf{9 5}}$ \\
\hline Wound class (\%) & & & & \\
I & $12(75.0)$ & $74(46.0)$ & Reference & $1.03-22.21$ \\
II & $2(12.5)$ & $59(36.6)$ & 4.78 & $0.23-16.36$ \\
III & $1(6.2)$ & $12(7.5)$ & 1.94 & $0.31-21.41$ \\
IV & $1(6.2)$ & $16(9.9)$ & 2.59 &
\end{tabular}

$\mathrm{OR}=$ odds ratio; $\mathrm{CI}_{95}=95 \%$ confidence interval.

*Adjusted $\mathrm{ORs}$ are presented for age, comorbidity score, and urinary catheter, which were independent risk factors for nosocomial infection in a logistic regression model. Crude $\mathrm{ORs}$ are presented for all other variables.

tOne patient had two nosocomial infections and is counted twice in this table.

fObtained from 6 of the hospitals.

According to the International Classification of Diseases, 9th revision, Clinical Modification.

Underlying illness score (see METHODS and Table 1). For statistical analyses, patients with a score of 2 or greater were pooled.

IRestricted to patients with surgery, but counting all nosocomial infections. For statistical analyses, patients with an American Society of Anesthesiologists score of 3 or 4 were pooled.

piratory tract infection is the contribution of viral agents such as respiratory syncytial virus. ${ }^{7}$ The strong seasonality of viral respiratory tract infections is likely to be reflected in the rate of nosocomial upper respiratory tract infections and lower respiratory tract infections. This likely explains the higher proportion of nosocomial infections caused by respiratory syncytial virus in other studies. ${ }^{7,10,20}$ Access to and use of accurate rapid diagnostic methods for respiratory syncytial virus may also influence the observed frequency of viral infections; such tests were routinely used in all of the hospitals participating in this study. Timing should therefore be considered when planning a survey of nosocomial infection or comparing pediatric nosocomial infection rates. Longitudinal studies are more likely to reflect the seasonality of viral nosocomial infections than are prevalence surveys. Analogous conclusions can be reached regarding viral gastrointestinal infections. Our survey was conducted in May, well after the respiratory syncytial virus, influenza, and rotavirus seasons, which may explain the relatively low rates of nosocomial respiratory tract infections and gastrointestinal tract infections observed.

The major pathogens causing nosocomial infections in this study were Enterobacteriaceae and coagulase-negative staphylococci. These findings correspond with findings from earlier surveys of nosocomial infection in pediatric hospitals and intensive care units. ${ }^{11,12,14}$ In contrast to nosocomial infections among adult patients, Staphylococcus aureus may play a smaller role in nosocomial infections among children. ${ }^{3,4}$ Viral pathogens were relatively rare in this study. ${ }^{7,10,20}$ As discussed above, this was most likely due to the timing of our survey.

It is well established that the use of indwelling devices increases the risk of nosocomial infection. , $^{3,7,10,11}$ Although limited information on device use was collected in this study, a significant association was observed between nosocomial infection and intravascular or uri-
TABLE 3

Distribution of the 35 Nosocomial Infections by ANATOMIC LOCATION

\begin{tabular}{|c|c|c|c|}
\hline & No. & $\%$ & $\begin{array}{l}\text { Per } 100 \\
\text { Patlents }\end{array}$ \\
\hline Bloodstream infection & 13 & 37.1 & 2.5 \\
\hline Clinical sepsis & 4 & 11.4 & 0.8 \\
\hline Laboratory confirmed ${ }^{*}$ & 9 & 25.7 & 1.7 \\
\hline Urinary tract infection & 7 & 20.0 & 1.3 \\
\hline Asymptomatic & 1 & 2.9 & 0.2 \\
\hline Symptomatic & 6 & 17.1 & 1.2 \\
\hline Surgical-site infection ${ }^{\dagger}$ & 6 & 17.1 & 3.2 \\
\hline Superficial-incisional & 4 & 11.4 & 2.1 \\
\hline Deep-incisional & 1 & 2.9 & 0.5 \\
\hline Organ-space & 1 & 2.9 & 0.5 \\
\hline Lower respiratory tract infection & 5 & 14.3 & 1.0 \\
\hline Bronchitis & 3 & 8.6 & 0.6 \\
\hline Pneumonia & 2 & 5.7 & 0.4 \\
\hline Gastrointestinal infection & 2 & 5.7 & 0.4 \\
\hline Gastroenteritis & 1 & 2.9 & 0.2 \\
\hline Intraabdominal & 1 & 2.9 & 0.2 \\
\hline Otitis media & 1 & 2.9 & 0.2 \\
\hline Sinusitis & 1 & 2.9 & 0.2 \\
\hline
\end{tabular}

*Four of the nine were caused by Enterobacteriaceae, three by coagulase-negative staphylococci, one by Streptococcus sanguis, and one by Enterococcus species.

${ }^{+}$Calculation of rate per 185 patients who underwent surgery 30 days or 12 months (if a foreign body was implanted) before the study day.

nary catheters. Device use was less frequent than among adult patients. ${ }^{3}$ A comparison with other published pediatric studies is not possible due to the lack of data.

Several comorbidity scores are used for case-mix adjustment in general adult patient populations. For example, the Charlson score, the Karnofsky index, and the McCabe and Jackson classification have been shown to 
TABLE 4

Multivariate Analysis of Risk Factors for Nosocomial Infections Among the Patients

\begin{tabular}{|c|c|c|c|c|c|}
\hline & Infected & Not Infected & OR & $\mathbf{C l}_{95}$ & $\boldsymbol{P}$ \\
\hline No. of patients* & 35 & 486 & & & \\
\hline \multicolumn{6}{|l|}{ Age $(\%)$} \\
\hline Neonate & $8(22.9)$ & $108(22.2)$ & 1.59 & $0.38-4.09$ & \\
\hline 1 to $12 \mathrm{mo}$ & $12(34.3)$ & $71(14.6)$ & 3.75 & $1.56-9.00$ & .003 \\
\hline 13 to $48 \mathrm{mo}$ & $4(11.4)$ & $67(13.8)$ & 1.24 & $0.40-4.34$ & \\
\hline 5 to $16 \mathrm{y}$ & $11(31.4)$ & $239(49.2)$ & Reference & & .01 \\
\hline \multicolumn{6}{|l|}{ Comorbidity score $(\%)^{\dagger}$} \\
\hline 0 & $21(60.0)$ & $353(72.6)$ & Reference & & .04 \\
\hline 1 & $5(14.3)$ & $78(16.0)$ & 1.08 & $0.39-3.03$ & .87 \\
\hline 2 & $8(22.9)$ & $49(10.1)$ & 2.85 & $1.20-6.80$ & .01 \\
\hline$>2$ & $1(2.9)$ & $6(1.2)$ & & & \\
\hline Urinary catheter (\%) & $6(17.1)$ & $37(7.6)$ & 2.55 & $0.97-6.75$ & .05 \\
\hline
\end{tabular}

$\mathrm{OR}=$ odds ratio; $\mathrm{CI}_{45}=95 \%$ confidence interval.

* One patient had two nosocomial infections and is counted twice in this table.

Underlying illness score (see METHODS and Table 1). For statistical analyses, patients with a score of 2 or greater were pooled.

TABLE 5

Microorganisms ISOLATED From the 24 Nosocomial INFECTIONS

\begin{tabular}{lcr}
\hline & No. & \% \\
\hline Enterobacteriaceae (Escherichia coli excluded) & 9 & 37.5 \\
Coagulase-negative staphylococci & 7 & 29.2 \\
Escherichia coli & 3 & 12.5 \\
Enterococcus species & 3 & 12.5 \\
Staphylococcus aureus & 1 & 4.2 \\
Streptococcus species & 1 & 4.2 \\
Pseudomonas aeruginosa & 1 & 4.2 \\
Other (Acinetobacter species and Bacillus species) & 2 & 8.3 \\
Polymicrobial (>1 pathogen isolated) & 4 & 16.7 \\
Respiratory syncytial virus & 1 & 4.2 \\
\hline
\end{tabular}

correlate with the risk of nosocomial infection in prevalence surveys. ${ }^{3,4}$ No such score has been established for the general pediatric patient population. A new comorbidity index, corresponding to an adapted version of the Charlson score, was used in this study. ${ }^{18}$ The result was promising, with a score of greater than 1 being significantly associated with an increased risk of nosocomial infection. Additional studies are needed to validate and further adapt this comorbidity score.

ASA score is an established predictor of surgicalsite infection among adults. ${ }^{19,23}$ However, there is little information about its performance among pediatric patients. In a prospective, multicenter, pediatric survey, no association was found between ASA score and the risk of wound infection. ${ }^{21}$ This was probably due to the high proportion of pediatric patients with a low ASA score. In the current study, the small number of surgical-site infections did not allow an evaluation of ASA score for this type of nosocomial infection. However, ASA score was significantly associated with an increased risk of any type of nosocomial infection among surgical patients. Therefore, ASA score may be useful as a more general comorbidity score. It remains to be determined whether this applies only to prevalence surveys that select for a patient population with a higher comorbidity rate.

This prevalence survey of nosocomial infections in Swiss children's hospitals supplied valuable information concerning the frequency of such infections and exogenous and endogenous risk factors. A new comorbidity score showed promising performance, and its validation in future studies seems warranted. ASA score may also be a predictor of the overall rate of nosocomial infection, when used in prevalence surveys of hospitalized children. Prevalence surveys are a simple and cost-effective method of assessing nosocomial infections and have great potential value for the prevention of these infections. This study suggests that prevalence surveys should be conducted on a regular basis in pediatric hospitals.

\section{REFERENCES}

1. Haley RW, Schaberg DR, Crossley KB, Von Allmen SD, McGowan JE Jr. Extra charges and prolongation of stay attributable to nosocomial infections: a prospective interhospital comparison. Am J Med 1981; 70:51-58.

2. Hospital Infections Program, National Center for Infectious Diseases, Centers for Disease Control. Public health focus: surveillance, prevention, and control of nosocomial infections. MMWR 1992;41:783-787.

3. Pittet D, Harbarth S, Ruef C, et al. Prevalence and risk factors for nosocomial infections in four university hospitals in Switzerland. Infect Control Hosp Epidemiol 1999;20:37-42.

4. Sax H, Pittet D, Swiss-NOSO network. Interhospital differences in nosocomial infection rates: importance of case-mix adjustment. Arch Intern Med 2002;162:2437-2442.

5. Harris JA. Pediatric nosocomial infections: children are not little adults. Infect Control Hosp Epidemiol 1997;18:739-742.

6. Burgner D, Dalton D, Hanlon M, Wong M, Kakakios A, Isaacs D. Repeated prevalence surveys of paediatric hospital-acquired infection. J Hosp Infect 1996;34:163-170. 
7. Ford-Jones EL, Mindorff CM, Langley JM, et al. Epidemiologic study of 4684 hospital-acquired infections in pediatric patients. Pediatr Infect Dis J 1989:8:668-675.

8. Gilio AE, Stape A, Pereira CR, Cardoso MF, Silva CV, Troster EJ. Risk factors for nosocomial infections in a critically ill pediatric population: a 25-month prospective cohort study. Infect Control Hosp Epidemiol $2000 ; 21: 340-342$

9. Langley JM, Hanakowski M, Leblanc JC. Unique epidemiology of nosocomial urinary tract infections in children. Am J Infect Control 2001;29:94-98.

10. Raymond J, Aujard Y. Nosocomial infections in pediatric patients: a European, multicenter prospective study. Infect Control Hosp Epidemiol $2000 ; 21: 260-263$.

11. Richards MJ, Edwards JR, Culver DH, Gaynes RP. Nosocomial infections in pediatric intensive care units in the United States. Pediatrics 1999;103:e39.

12. Signorelli C, D'Alessandro D, Collina D, Fara GM. Prevalence survey of nosocomial infections in a paediatric hospital. $J$ Hosp Infect 1991; 18:139-143.

13. Singh-Naz N, Sprague BM, Patel KM, Pollack MM. Risk assessment and standardized nosocomial infection rate in critically ill children. Crit Care Med 2000;28:2069-2075.

14. Sohn AH, Garrett DO, Sinkowitz-Cochran RL, et al. Prevalence of nosocomial infections in neonatal intensive care unit patients: results from the first national point-prevalence survey. J Pediatr 2001;139:821 827.
15. Haley RW, Culver DH, White JW, et al. The efficacy of infection surveillance and control programs in preventing nosocomial infections in US hospitals. Am J Epidemiol 1985;121:182-205.

16. Garner JS, Jarvis WR, Emori TG, Horan TC, Hughes JM. CDC definitions for nosocomial infections, 1988. Am J Infect Control 1988;16:128140.

17. U.S. Public Health Service. International Classification of Diseases, 9 th Revision, Clinical Modification: ICD-9-CM. Washington, DC: U.S. Public Health Service; 1989. Publication PHS 89-1260.

18. Charlson ME, Pompei P, Ales KL, MacKenzie CR. A new method of classifying prognostic comorbidity in longitudinal studies: development and validation. Journal of Chronic Diseases 1987;40:373-383.

19. Emori TG, Culver DH, Horan TC, et al. National Nosocomial Infections Surveillance System (NNIS): description of surveillance methods. $A m$ Infect Control 1991;19:19-35.

20. Welliver RC, McLaughlin S. Unique epidemiology of nosocomial infection in a children's hospital. Am J Dis Child 1984;138:131-135.

21. Horwitz JR, Chwals WJ, Doski JJ, Suescun EA, Cheu HW, Lally KP. Pediatric wound infections: a prospective multicenter study. Ann Surg 1998;227:553-558.

22. Weigeit JA, Dryer D, Haley RW. The necessity and efficiency of wound surveillance after discharge. Arch Surg 1992;127:77-82.

23. National Nosocomial Infections Surveillance (NNIS) System. National Nosocomial Infections Surveillance (NNIS) System report: data summary from January 1992-June 2001, issued August 2001. Am J Infect Control 2001;29:404-421. 